\title{
Is Visceral Fat the Missing Link in the Relationship Between Inflammation and Insulin Resistance in RA?
}

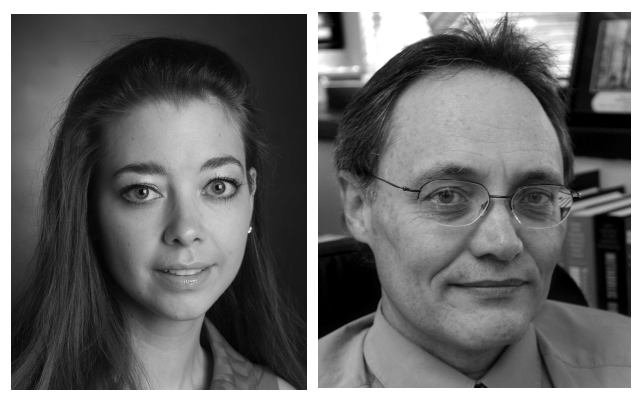

Several groups of investigators evaluating insulin resistance in rheumatoid arthritis (RA; Table 1) $)^{1,2,3,4,5,6,7,8,9}$ have reported that patients with RA have more insulin resistance than non-RA control subjects, even with similar body mass index (BMI) $)^{1,2,3,4,5}$. In many RA studies, insulin resistance was associated with markers of inflammation or disease activity $^{5,6,7,8}$. Moreover, some studies that examined insulin resistance before and after treatment of RA with anti-tumor necrosis factor- $\alpha$ (TNF- $\alpha$ ) or antiinterleukin 6 (IL-6) agents found that treatment with these drugs, and presumably the consequent decrease in inflammation, resulted in a significant improvement in insulin sensitivity ${ }^{10,11}$. These and other studies provide support for the notion that inflammation in RA promotes insulin resistance.

The concept that there is a relationship between the inflammation in RA and insulin resistance is also supported by studies performed in animals showing that inflammation promotes insulin resistance. For example, administration of TNF- $\alpha$ and IL- 6 caused insulin resistance in rats and mice ${ }^{12,13}$. This finding is not surprising because cytokines such as IL- 6 and TNF- $\alpha$ contribute to insulin resistance through downstream repression of insulin signaling (reviewed ${ }^{14}$ ).

In this issue of The Journal, AbouAssi and colleagues present a meticulous and thorough evaluation of insulin sensitivity in 39 patients with RA and 39 control subjects matched for not only age and sex, but also for BMI and physical activity ${ }^{15}$. Insulin sensitivity was quantified by frequently sampled intravenous glucose tolerance test (FSIVGTT). Factors assessed were disease activity, levels of proinflammatory cytokines, and potential confounders including physical activity measured by accelerometry over 7 days and adiposity determined by computerized tomography of the abdomen and thigh.

Three of their findings were unexpected and therefore thought-provoking: (1) insulin resistance was not increased in RA, (2) inflammation was not independently associated with insulin resistance, and (3) visceral adiposity was not increased in RA. We discuss some interpretations of the findings below.

Potential explanations for the finding that insulin sensitivity was not significantly altered in patients with RA compared to controls (in contrast to the studies described earlier) seem most likely to be found in the patient population studied and the method for measuring insulin sensitivity.

The RA patient population studied is similar to that in several other studies with respect to age, race, sex, disease duration, and seropositivity. One difference was that patients were excluded for use of any medication known to affect carbohydrate or lipid metabolism (such as statins, angiotensin-converting enzyme inhibitors, $\beta$-blockers, and angiotensin receptor blockers). This strategy has the important benefit of reducing the confounding effect of drugs on insulin sensitivity, but it has the potential disadvantage of decreasing generalizability by excluding many patients receiving treatment for hypertension and hyperlipidemia, 2 components of the metabolic syndrome. A second difference, reflecting therapeutic advances and changes in practice, was that a larger proportion (about $50 \%$ ) of patients was receiving therapy with biologic agents; some biologic agents may improve insulin sensitivity in patients with RA ${ }^{10,11}$.

To measure insulin resistance/sensitivity, the investigators used the FSIVGTT. This contrasts with many of the previous studies, which used the simpler and less rigorous fasting homeostatic model assessment of insulin resistance (HOMA-IR) to evaluate insulin resistance in RA (Table 1). As the authors indicate, the fasting HOMA-IR reflects mostly hepatic insulin resistance and hepatic glucose production, rather than peripheral insulin sensitivity. The FSIVGTT method used by the investigators includes both hepatic and peripheral insulin sensitivity (reviewed ${ }^{16}$ ), but peripheral insulin sensitivity would likely be a much greater

See Adipose depots and insulin resistance in RA, page 1974 
Table 1. Select publications evaluating insulin resistance in RA versus non-RA control subjects.

\begin{tabular}{|c|c|c|c|c|c|}
\hline Reference & No. Subjects & BMI & Visceral Fat & Insulin Resistance/sensitivity & Notes \\
\hline Ferraz-Amaro $2011^{1}$ & $\begin{array}{l}16 \text { RA starting anti-TNF, } \\
34 \text { RA control, and } \\
70 \text { healthy control }\end{array}$ & $\begin{array}{l}\text { Non-significant trend for } \\
\text { lower in RA }\end{array}$ & $\begin{array}{l}\text { ND in controls, } \\
\text { in RA unchanged } \\
\text { after anti-TNF- } \alpha\end{array}$ & $\begin{array}{l}\text { Greater IR (HOMA2-IR) } \\
\text { in RA }\end{array}$ & \\
\hline Ferraz-Amaro $2013^{2}$ & $101 \mathrm{RA}, 99$ control & Similar & $\begin{array}{l}\mathrm{ND} \text {, but trend for } \\
\text { larger waist in RA }\end{array}$ & $\begin{array}{l}\text { Greater IR (HOMA-IR) and } \\
\text { impaired insulin processing } \\
\text { (split proinsulin levels) in RA }\end{array}$ & \\
\hline Rosenvinge $2007^{4}$ & 9 RA, 9 control & Similar & $\mathrm{ND}$ & $\begin{array}{l}\text { Greater IR (hyperinsulinemic } \\
\text { euglycemic clamp) in RA. }\end{array}$ & $\begin{array}{l}\text { Average BMI } \\
\text { overweight }\end{array}$ \\
\hline Paolisso $1991^{5}$ & $\begin{array}{l}8 \text { RA (+8 with other } \\
\text { CTD), } 10 \text { healthy control }\end{array}$ & Similar & ND & $\begin{array}{l}\text { Greater IR (IVGTT } \\
\text { and hyperinsulinemic } \\
\text { euglycemic clamp) in the } \\
\text { RA/CTD group }\end{array}$ & $\begin{array}{l}\text { Average BMI } \\
\text { overweight. IR did } \\
\text { not improve after } \\
\text { anti-TNF }\end{array}$ \\
\hline Hoes $2011^{7}$ & $\begin{array}{l}140 \text { RA, } 50 \text { controls } \\
\text { (selected for normal } \\
\text { glucose tolerance) }\end{array}$ & Lower in RA & $\begin{array}{l}\mathrm{ND} \text {, but lower waist } \\
\text { circumference in RA }\end{array}$ & $\begin{array}{l}\text { Decreased IS and beta } \\
\text { cell function (FSOGTT) } \\
\text { in RA }\end{array}$ & $\begin{array}{l}\text { Premenopausal } \\
\text { females. BMI limit } \\
18-25 \mathrm{~kg} / \mathrm{m}^{2}\end{array}$ \\
\hline Dessein $2002^{8}$ & $\begin{array}{l}38 \text { RA (+49 with other } \\
\text { CTD), } 30 \text { control }\end{array}$ & Higher in RA/CTD & ND & $\begin{array}{l}\text { Greater IR (HOMA-IR and } \\
\text { QUICKI) in RA/CTD, } \\
\text { but no difference after } \\
\text { adjustment for ESR and BMI }\end{array}$ & $\begin{array}{l}\text { More females in RA } \\
\text { group. RA waist } \\
\text { circumference } \\
\text { associated with all } \\
\text { measures of IS }\end{array}$ \\
\hline Toussirot $2013^{9}$ & $30 \mathrm{RA}, 51$ control & Similar & $\begin{array}{l}\text { Greater visceral fat } \\
\text { in RA by DEXA }\end{array}$ & Similar IR (HOMA-IR) & \\
\hline
\end{tabular}

RA: rheumatoid arthritis; BMI: body mass index; DEXA: dual-energy X-ray absorptiometry; IR: insulin resistance; HOMA-IR: homeostatic model assessment of insulin resistance; ND: not done; IS: insulin sensitivity; FSOGTT: frequently sampled oral glucose tolerance test; OGTT: oral glucose tolerance test, IVGTT: intravenous glucose tolerance test; CTD: connective tissue disease; QUICKI: quantitative insulin sensitivity check index; TNF: tumor necrosis factor; AUC: area under the curve; IL: interleukin; ESR: erythrocyte sedimentation rate.

contributor. Thus, one possibility is that RA affects insulin sensitivity of the liver to a greater extent than the peripheral tissues.

The authors found that IL-6, but not C-reactive protein (CRP) or 28-joint Disease Activity Score (DAS28), was weakly associated with insulin resistance in RA. One consideration is that this unimpressive relationship between inflammation and insulin resistance may have been affected not only by the RA population studied, but also by their relatively low disease activity. The average DAS28 score of 3.1 is not unusual, but over $40 \%$ of patients were in remission, and CRP was not higher in the patients with RA (although IL- 6 and TNF- $\alpha$ were). IL- 6 , one of the proinflammatory cytokines increased in the patients with RA, was correlated with insulin sensitivity only in univariate analysis $(\rho=-0.3, p=0.05)$; however, visceral adiposity was more strongly associated with insulin sensitivity, independent of IL-6 concentrations $(p=0.005)$. One can speculate that if the degree of inflammation in the subjects with RA had been higher, IL- 6 might have been the stronger predictor of insulin sensitivity.
Total adiposity was found to be similar in RA and control subjects, but contrary to much of the literature $9,16,17,18$ (Table 1), visceral adiposity was about $25 \%$ lower among patients with RA. Given the matching for physical activity between RA and control subjects, this observation could suggest that the previously observed increase in visceral adiposity (and decrease in muscle mass) in RA is mainly due to inactivity. A different study, however, showed that RA patients with similar levels of physical activity to control subjects had greater central obesity and higher fat mass ${ }^{7}$. Thus, the lower visceral adiposity observed in the RA patients in the current study may have been related to patient selection (i.e., exclusions for many antihypertensive and lipid-lowering drugs leading to a lower proportion of patients with metabolic syndrome, as discussed), but it also suggests new possibilities regarding the relationship between visceral fat, inflammation, and insulin resistance in RA.

The authors found that visceral adiposity and waist circumference, which could be considered a surrogate for visceral adiposity, were most strongly independently

Personal non-commercial use only. The Journal of Rheumatology Copyright (C) 2014. All rights reserved 
associated (inversely) with insulin sensitivity in statistical models that focused on clinical variables and in models focused on laboratory variables. Although IL-6 concentrations were significantly inversely correlated with insulin sensitivity, this relationship was not independent of visceral adiposity. We wonder if the visceral adiposity is particularly important to insulin resistance in RA, and if the 2 synergistically contribute to insulin resistance in RA. Thus, the lower visceral adiposity in this group of patients may have contributed to the authors finding no significant alterations in insulin sensitivity.

Visceral fat may be altered in a state of high inflammation. For example, comparing RA and control subjects with the highest quartile of visceral adipose tissue, patients with RA had a $29 \%$ greater probability of elevated fasting blood glucose compared to control subjects ${ }^{19}$, raising the possibility that an interaction between visceral adipose tissue and inflammation contributes to insulin resistance.

Adipose tissue is an organ containing members of the innate and acquired immune systems. Macrophages accumulate to a greater extent in visceral than subcutaneous adipose tissue, and their proinflammatory cytokine release is considered a major contributor to the increased insulin resistance associated with obesity (reviewed ${ }^{20}$ ).

The role of cytokines in adipose tissue is complex. Systemically, proinflammatory cytokines promote insulin resistance through direct effects on insulin signaling and indirect effects by stimulating lipolysis; however, locally within the adipose tissue, IL-6 has a protective, homeostatic role. For example, obese mice with inactivated IL-6 receptor paradoxically showed increased tissue inflammation with greater proportion of proinflammatory M1 macrophages and insulin resistance ${ }^{21}$.

There is little information about how exactly RA affects adipose tissue, particularly in the visceral compartment. Perhaps in the setting of excess systemic inflammation as seen in RA, the homeostatic function of IL-6 within adipose tissue is deranged. Interestingly, a study that compared paired samples of articular and subcutaneous adipose tissue from patients with RA found a similar degree of infiltration of M2 macrophages, which would typically promote healing and secrete antiinflammatory cytokines. The M2 macrophages from the articular adipose tissue, however, were primed to produce an exaggerated inflammatory response to stimuli compared to those from the subcutaneous fat ${ }^{22}$. Although that study did not examine visceral fat, it showed altered function of macrophages within adipose tissue, which had likely been chronically exposed to high levels of proinflammatory cytokines.

The interesting clinical study reported by AbouAssi and colleagues provides new insights into insulin resistance in RA and has raised many questions about the relationship between visceral fat, inflammation, and insulin resistance, not only in RA but also in other diseases.
MICHELLE J. ORMSETH, MD, MSCI;

Division of Rheumatology,

Department of Medicine;

C. MICHAEL STEIN,

Division of Rheumatology,

Department of Medicine and Division of Clinical Pharmacology, Department of Pharmacology,

Vanderbilt University, Nashville, Tennessee, USA.

Supported by US National Institutes of Health grants: P60 AR056116 Address correspondence to Dr. Ormseth, 1161 21st Ave. South, T-3113 MCN, Nashville, Tennessee 37232-2681, USA; E-mail:

michelle.ormseth@vanderbilt.edu

\section{REFERENCES}

1. Ferraz-Amaro I, Arce-Franco M, Muniz J, Lopez-Fernandez J, Hernandez-Hernandez V, Franco A, et al. Systemic blockade of TNF-alpha does not improve insulin resistance in humans. Horm Metab Res 2011;43:801-8.

2. Ferraz-Amaro I, Garcia-Dopico JA, Medina-Vega L, Gonzalez-Gay MA, Diaz-Gonzalez F. Impaired beta cell function is present in nondiabetic rheumatoid arthritis patients. Arthritis Res Ther 2013;15:R17.

3. Chung CP, Oeser A, Solus JF, Avalos I, Gebretsadik T, Shintani A et al. Prevalence of the metabolic syndrome is increased in rheumatoid arthritis and is associated with coronary atherosclerosis. Atherosclerosis 2008; 196:756-63.

4. Rosenvinge A, Krogh-Madsen R, Baslund B, Pedersen BK. Insulin resistance in patients with rheumatoid arthritis: effect of anti-TNFalpha therapy. Scand J Rheumatol 2007;36:91-6.

5. Paolisso G, Valentini G, Giugliano D, Marrazzo G, Tirri R, Gallo $\mathrm{M}$, et al. Evidence for peripheral impaired glucose handling in patients with connective tissue diseases. Metabolism 1991; 40:902-7.

6. Penesova A, Radikova Z, Vlcek M, Kerlik J, Lukac J, Rovensky J, et al. Chronic inflammation and low-dose glucocorticoid effects on glucose metabolism in premenopausal females with rheumatoid arthritis free of conventional metabolic risk factors. Physiol Res 2013;62:75-83.

7. Hoes JN, van der Goes MC, van Raalte DH, van der Zijl NJ, den Uyl D, Lems WF, et al. Glucose tolerance, insulin sensitivity and beta-cell function in patients with rheumatoid arthritis treated with or without low-to-medium dose glucocorticoids. Ann Rheum Dis 2011;70:1887-94.

8. Dessein PH, Joffe BI, Stanwix A, Botha AS, Moomal Z. The acute phase response does not fully predict the presence of insulin resistance and dyslipidemia in inflammatory arthritis. J Rheumatol 2002;29:462-6

9. Toussirot E, Grandclement E, Gaugler B, Michel F, Wendling D, Saas $\mathrm{P}$, et al. Serum adipokines and adipose tissue distribution in rheumatoid arthritis and ankylosing spondylitis. A comparative study. Front Immunol 2013;4:453.

10. Stagakis I, Bertsias G, Karvounaris S, Kavousanaki M, Virla D, Raptopoulou A, et al. Anti-tumor necrosis factor therapy improves insulin resistance, beta cell function and insulin signaling in active rheumatoid arthritis patients with high insulin resistance. Arthritis Res Ther 2012;14:R141

11. Schultz O, Oberhauser F, Saech J, Rubbert-Roth A, Hahn M, Krone $\mathrm{W}$, et al. Effects of inhibition of interleukin-6 signalling on insulin sensitivity and lipoprotein (a) levels in human subjects with rheumatoid diseases. PloS One 2010;5:e14328.

12. Feingold KR, Soued M, Staprans I, Gavin LA, Donahue ME, Huang BJ, et al. Effect of tumor necrosis factor (TNF) on lipid metabolism in the diabetic rat. Evidence that inhibition of adipose 
tissue lipoprotein lipase activity is not required for TNF-induced hyperlipidemia. J Clin Invest 1989;83:1116-21.

13. Kim HJ, Higashimori T, Park SY, Choi H, Dong J, Kim YJ, et al. Differential effects of interleukin-6 and -10 on skeletal muscle and liver insulin action in vivo. Diabetes 2004;53:1060-7.

14. Osborn O, Olefsky JM. The cellular and signaling networks linking the immune system and metabolism in disease. Nat Med 2012;18:363-74.

15. AbouAssi H, Tune KN, Gilmore B, Bateman LA, McDaniel G, Muehlbauer M, et al. Adipose depots, not disease-related factors, account for skeletal muscle insulin sensitivity in established and treated rheumatoid arthritis. J Rheumatol 2014;41:1974-9.

16. Muniyappa R, Lee S, Chen H, Quon MJ. Current approaches for assessing insulin sensitivity and resistance in vivo: advantages, limitations, and appropriate usage. Am J Physiol Endocrinol Metab 2008;294:E15-26.

17. Elkan AC, Hakansson N, Frostegard J, Hafstrom I. Low level of physical activity in women with rheumatoid arthritis is associated with cardiovascular risk factors but not with body fat mass - a cross sectional study. BMC Musculoskelet Disord 2011;12:13.
18. Giles JT, Ling SM, Ferrucci L, Bartlett SJ, Andersen RE, Towns M, et al. Abnormal body composition phenotypes in older rheumatoid arthritis patients: association with disease characteristics and pharmacotherapies. Arthritis Rheum 2008;59:807-15.

19. Giles JT, Allison M, Blumenthal RS, Post W, Gelber AC, Petri M, et al. Abdominal adiposity in rheumatoid arthritis: association with cardiometabolic risk factors and disease characteristics. Arthritis Rheum 2010;62:3173-82.

20. Esser N, Legrand-Poels S, Piette J, Scheen AJ, Paquot N. Inflammation as a link between obesity, metabolic syndrome and type 2 diabetes. Diabetes Res Clin Pract 2014; Apr 13 (E-pub ahead of print).

21. Mauer J, Chaurasia B, Goldau J, Vogt MC, Ruud J, Nguyen KD, et al. Signaling by IL-6 promotes alternative activation of macrophages to limit endotoxemia and obesity-associated resistance to insulin. Nat Immunol 2014;15:423-30.

22. Kontny E, Prochorec-Sobieszek M. Articular adipose tissue resident macrophages in rheumatoid arthritis patients: potential contribution to local abnormalities. Rheumatology 2013;52:2158-67.

J Rheumatol 2014;41:1906-9; doi:10.3899/jrheum.140780 